\title{
atrB-Associated Fludioxonil Resistance in Botrytis fragariae Not Linked to Mutations in Transcription Factor mrr 1
}

\author{
Meng-Jun Hu, ${ }^{1}$ Scott Cosseboom, ${ }^{1}$ and Guido Schnabel ${ }^{2, \dagger}$ \\ ${ }^{1}$ Department of Plant Science and Landscape Architecture, University of Maryland, College Park, MD; and 2Department of Agricultural and \\ Environmental Sciences, Clemson University, Clemson, SC \\ Accepted for publication 7 December 2018.
}

\begin{abstract}
Resistance to fludioxonil in Botrytis cinerea and B. fragariae was previously found to be linked to either overexpression of the drug efflux pump atrB activated by mutations in transcription factor $m r r l$ or to mutations in the osmoregulation gene osl. In the present study, isolates of $B$. cinerea, Botrytis group $\mathrm{S}$, or $B$. fragariae collected from strawberry fields in the United States were resistant to fludioxonil with half-maximal effective concentration values ranging from 0.04 to $0.43 \mu \mathrm{g} / \mathrm{ml}$ for B. cinerea, 0.03 to $1.03 \mu \mathrm{g} / \mathrm{ml}$ for Botrytis group S, and 0.28 to $3.48 \mu \mathrm{g} / \mathrm{ml}$ for $B$. fragariae. Analyses of $m r r l$ sequences revealed various mutations linked to fludioxonil resistance in B. cinerea and Botrytis group $\mathrm{S}$ isolates. However, no mutations in $\mathrm{mrrl}$ correlated with $\operatorname{atr} B$

increased $a t r B$ copy numbers could explain the $\operatorname{atr} B$ overexpression in these $B$. fragariae isolates. Mutations in os 1 conferred resistance to iprodione in B. cinerea and Botrytis group S isolates; none correlated with resistance to fludioxonil in $B$. fragariae. In contrast to European isolates, U.S. B. fragariae isolates contained a 3-bp insertion in the coding region of os 1. These isolates were more sensitive to osmotic stress but it is unclear whether the insertion is responsible for this phenotype. Our findings suggest that $\operatorname{atr} B$ overexpression-associated fludioxonil resistance is an across-species mechanism of resistance to fludioxonil that can be induced by mutations in $m r r l$ and other, still-unknown mechanisms.
\end{abstract} overexpression-mediated resistance in $B$. fragariae isolates. Neither nucleotide variations in the 1,370-bp upstream region of $\operatorname{atr} B$ nor

Botrytis fragariae is a newly described fungal pathogen on strawberry (Rupp et al. 2017) and was frequently detected in fields in Germany and the United States (Dowling et al. 2017; Hu et al. 2018; Rupp et al. 2017). B. fragariae was reported to be a strawberry-specific pathogen displaying less aggressiveness on nonstrawberry tissues (Rupp et al. 2017). The species is primarily found on strawberry flowers but can also cause gray mold of fruit (Dowling et al. 2017). Our previous studies have shown that 66 of 188 Botrytis isolates collected in strawberry fields in the MidAtlantic United States were B. fragariae (Dowling et al. 2018). Despite distinct infection behavior and genetic background, both $B$. cinerea and $B$. fragariae have developed resistance to multiple chemical classes of fungicides, including the phenylpyrrole (PP) fungicide fludioxonil (Hu et al. 2018; Rupp et al. 2017). In fact, higher frequencies of resistance to fludioxonil were found in B. fragariae compared with B. cinerea (Dowling et al. 2018).

Resistance to fludioxonil in $B$. cinerea is primarily conferred by overexpression of drug efflux transporters. Kretschmer et al. (2009) first documented B. cinerea isolates with resistance to fludioxonil, defined as the MDR1 phenotype. The resistance was found to be associated with mutations in transcription factor $m r r l$ causing overexpression of $a t r B$, an ATP-binding cassette (ABC) transporter (Kretschmer et al. 2009). Isolates with higher levels of resistance to fludioxonil are classified into $B$. cinerea group $\mathrm{S}$ and designated as the MDR1h phenotype. A 3-bp deletion mutation in $m r r l$, leading to an amino acid deletion of L497, was found to be correlated with MDR1h isolates in Botrytis group S (Leroch et al. 2012). Except for

${ }^{\dagger}$ Corresponding author: G. Schnabel; E-mail: schnabe@clemson.edu

Funding: This material is based upon work supported by NIFA/USDA under project numbers SC-1700501 and SCRI 2014-51181-22377.

The author(s) declare no conflict of interest.

(c) 2019 The American Phytopathological Society
Keywords: Disease control, disease management, genetics, resistance. $m r r l$, only mutations in the group III histidine kinase gene os $l$ have been reported to be linked to high levels of fludioxonil resistance in B. cinerea. Ren et al. (2016) identified mutations in the HAMP domains of the N-terminal region or in the HATPase_c domain of the C-terminal region of $o s 1$ in both field isolates and laboratory mutants. With regard to $B$. fragariae, the mechanism underlying resistance to fludioxonil thus far has been found to be C588Y or R632I mutations in $m r r l$, which are identical to the MDR1-realated mutation in B. cinerea (Rupp et al. 2017).

Cross-resistance between PPs and dicarboxamides (DCs) is common in Botrytis isolates (Faretra and Pollastro 1993; Fillinger et al. 2012; Leroux et al. 1999; Ren et al. 2016), because both chemical classes of fungicides are believed to interfere with osmotic signal transduction. However, this cross-resistance seemed to be inconclusive for MDR1 isolates based on previous studies. Kretschmer et al. (2009) found no significant difference between non-MDR1 and MDR1 isolates in the sensitivity to the DC fungicide iprodione. In contrast, Li et al. (2014) found that all MDR1 isolates resistant to fludioxonil were also resistant to iprodione, indicating the cross-resistance between the two chemical classes. However, iprodione target gene os 1 was not investigated in the MDR1 isolates of the latter study. Crossresistance in MDR1 isolates between fludioxonil and tolnaftate or fludioxonil and cyprodinil was identified in previous studies (Kretschmer et al. 2009).

The objectives of this study were to determine the sensitivity of $B$. fragariae to fludioxonil and potential cross-resistance to iprodione, cyprodinil, or tolnaftate and to investigate the resistance mechanism associated with fludioxonil resistance.

\section{MATERIALS AND METHODS}

Collection, selection, and identification of Botrytis spp. isolates. Botrytis spp. isolates used in this study were selected from a pool of previously collected Botrytis isolates (in 2015 or 2016) from six southeastern United States, including South Carolina, 
North Carolina, Georgia, Maryland, Arkansas, and Virginia (Table 1). All isolates were collected from annual strawberry plants that were not subjected to single-site fungicide treatments after planting (except four isolates from fruit) (Table 1). However, the isolates may have been subjected to fungicide pressure at the nursery level. Isolates had been characterized for their fungicide resistance profile (data not shown), as described previously (Fernández-Ortuño et al. 2014; Schnabel et al. 2015). Botrytis isolates with low and high levels of fludioxonil resistance, along with some sensitive isolates, were selected for the study. One German B. fragariae isolate (D11-H-R4) (Rupp et al. 2017) was kindly provided by Dr. Matthias Hahn at University of Kaiserslautern in Germany. Two B. cinerea isolates (106-6-14 and 107-8-14), characterized as MDR1h isolates previously (Chen et al. 2016), were also included in this study. All isolates used in this study were generated from single spores.

Botrytis isolates were grown on potato dextrose agar (PDA) at $22^{\circ} \mathrm{C}$ for 5 days in darkness. Agar plugs containing mycelia were then transferred to $250-\mathrm{ml}$ flasks containing $50 \mathrm{ml}$ of potato dextrose broth. After 3 days of incubation, mycelium was removed from the broth and subject to DNA extraction using the DNeasy Plant Mini Kit (Qiagen, Valencia, CA, U.S.A.). Species-specific primers (CFM_NEP2, C_NEP2, F_NEP2, and M_NEP2) developed previously (Dowling et al. 2017) were used to identify Botrytis spp. isolates collected from strawberry to the species level. Polymerase chain reactions (PCRs) were carried out in a $25-\mu 1$ system containing $10 \mathrm{ng}$ of template DNA, $0.4 \mu \mathrm{M}$ each primer, $200 \mu \mathrm{M}$ dNTP, $1 \times$ PCR buffer (New England Biolabs), and $1 \mathrm{U}$ of Taq DNA polymerase (New England Biolabs). The amplification program consisted of an initial denaturation at $94^{\circ} \mathrm{C}$ for $3 \mathrm{~min}$; followed by 34 cycles of $94^{\circ} \mathrm{C}$ for $40 \mathrm{~s}$, annealing at $55^{\circ} \mathrm{C}$ for $40 \mathrm{~s}$, and extension at $72^{\circ} \mathrm{C}$ for $1 \mathrm{~min}$; and a final extension of $72^{\circ} \mathrm{C}$ for $10 \mathrm{~min}$. PCR products were separated on a $1 \%$ (wt/vol) agarose gel in $0.5 \%$ Tris-acetate-EDTA buffer for $30 \mathrm{~min}$ at $100 \mathrm{~V}$. The gel was then stained with GelRed (Biotium Inc., Fremont, CA, U.S.A.) and exposed to UV light to visualize DNA fragments.

In vitro fungicide sensitivity assays. Sensitivity of Botrytis spp. isolates to fludioxonil (Scholar; Syngenta, Greensboro, NC, U.S.A.), cyprodinil (Vangard; Syngenta), iprodione (Rovral; Bayer Crop Science, Research Triangle Park, NC, U.S.A.), or tolnaftate (Sigma-Aldrich, St. Louis, MO, U.S.A.) was determined using a spore-based microtiter assay (Stammler and Speakman 2006). To make conidial suspensions, isolates were grown on PDA (Difco) plates at $22^{\circ} \mathrm{C}$ for 5 days in darkness, followed by 1 week of incubation under light conditions. Spores were then harvested in
$3 \mathrm{ml}$ of double concentrated malt extract broth $(2 \times \mathrm{MEB})$ by gently scratching the colonies using a sterilized cotton swab. The resulting suspensions were filtered with two-layer cloth and diluted to $5 \times 10^{4}$ spores/ml. Final fungicidal concentrations of $0,0.1,0.3,1,3,10$, 30 , and $100 \mu \mathrm{g} / \mathrm{ml}$ were used in microtiter assays for fludioxonil, cyprodinil, and iprodione, while $0,0.03,0.1,0.3,1,3,10$, and 30 $\mu \mathrm{g} / \mathrm{ml}$ were used for tolnaftate. Fungicide solutions were prepared in sterilized water and each solution $(50 \mu \mathrm{l})$ was transferred into 96-well microtiter plates and mixed with an equal volume $(50 \mu \mathrm{l})$ of spore suspension, as described previously (Hu et al. 2015). Each isolate and fungicide concentration had three replicates. After 2 days of incubation at $22^{\circ} \mathrm{C}$ in darkness, absorbance of $600 \mathrm{~nm}$ was determined with a photometer. A linear regression analysis was performed to calculate the half-maximal effective concentration $\left(\mathrm{EC}_{50}\right)$ values for each isolate. In case a poor correlation coefficient was observed, the experiment was then repeated for that isolate.

In addition to determining the $\mathrm{EC}_{50}$ as described above, the $90 \%$ mycelial growth inhibition $\left(\mathrm{EC}_{90}\right)$ value was determined for fludioxonil. Briefly, isolates were grown on malt extract agar media amended with fludioxonil at $0,3,10$, and $100 \mu \mathrm{g} / \mathrm{ml}$. After 1 week of incubation at $22^{\circ} \mathrm{C}$ in the dark, mycelial growth inhibition $\geq 90 \%$ was measured. $\mathrm{EC}_{90}$ value was expressed as greater or smaller than 3,10, or $100 \mu \mathrm{g} / \mathrm{ml}$ for each isolate.

Detached-fruit assay. A selection of $B$. cinerea, Botrytis group $\mathrm{S}$, and $B$. fragariae isolates (nine in total) with various sensitivities to fludioxonil were chosen to be tested for practical resistance to fludioxonil (Table 2). Store-bought, organic strawberry fruit were treated with the recommended label rate $(410 \mu \mathrm{g} / \mathrm{ml})$ of fludioxonil using the formulated product Scholar (Syngenta). The diluted fungicide was applied to strawberry fruit using a spray bottle until runoff; then, the fruit were allowed to dry for $2 \mathrm{~h}$. The strawberry fruit were then wounded by inserting a sterile toothpick to a depth of $1 \mathrm{~cm}$ into the receptacle of each fruit. Because some isolates did not easily sporulate, mycelia of each isolate were transferred into the wound for seven fruit per isolate. Seven other strawberry fruit were treated with fludioxonil and wounded but were not inoculated. The fruit were incubated in humid chambers for 5 days, and then incidence of gray mold and lesion diameter was evaluated for each fruit. This experiment was conducted twice. A Kruskal-Wallis test was used to test the effect of isolate on lesion diameter, and was followed by a Dunn's multiple comparisons test.

Sequencing of $\mathbf{m r r} 1$ and os 1 in Botrytis spp. isolates. Mrrl and os 1 genes were amplified and sequenced from $B$. cinerea and $B$. fragariae in order to investigate the molecular basis of resistance to fludioxonil. Primer information, including name, nucleotide

TABLE 1. Strawberry Botrytis spp. isolates used in this study and their characteristics regarding the sensitivity to fludioxonil

\begin{tabular}{|c|c|c|c|c|c|c|c|c|}
\hline Isolates & $\mathrm{EC}_{50}$ & $\mathrm{EC}_{90} \mathrm{x}$ & Sensitivity ${ }^{y}$ & AA alteration in $m r r l$ & Species & Phenotype & Host tissue & Location \\
\hline $4-8-15$ & 0.04 & $<3$ & $S$ & None & Botrytis cinerea & Non-MDR & Fruit & Anderson, SC \\
\hline $27-5-16$ & 0.43 & $<3$ & LR & $\mathrm{R} 351 \mathrm{C}$ & B. cinerea & MDR1 & Flower & Lancaster, SC \\
\hline $5 \mathrm{~d} 5$ & 0.03 & $<3$ & $\mathrm{~S}$ & $\mathrm{~T} 449 \mathrm{~S} / \mathrm{G} 702 \mathrm{~N}$ & Botrytis group $\mathrm{S}$ & Non-MDR & Flower & Spartanburg, SC \\
\hline $6-3-15$ & 0.29 & $<3$ & LR & D354Y/G702N & Botrytis group $\mathrm{S}$ & MDR1 & Fruit & Chesterfield, SC \\
\hline $18-3-16$ & 1.03 & $<3$ & MR & $\Delta \mathrm{L} / \mathrm{V} 497$ & Botrytis group $\mathrm{S}$ & MDR1h & Flower & Duplin, NC \\
\hline $106-6-14$ & 1.32 & $>100$ & MR & $\Delta \mathrm{L} / \mathrm{V} 497$ & Botrytis group $\mathrm{S}$ & MDR1h & Fruit & Tolland, CT \\
\hline $107-8-14$ & 2.22 & $>100$ & MR & $\Delta \mathrm{L} / \mathrm{V} 497$ & Botrytis group $\mathrm{S}$ & MDR1h & Flower & Tolland, CT \\
\hline D11-H-R4z & 0.22 & $<3$ & S & None & B. fragariae & Non-MDR & Flower & Germany \\
\hline $12-3-16$ & 0.28 & $<3$ & $\mathrm{~S}$ & None & B. fragariae & Non-MDR & Flower & York, SC \\
\hline $11-1-16$ & 0.32 & $<3$ & $\mathrm{~S}$ & None & B. fragariae & Non-MDR & Fruit & Colquitt, GA \\
\hline $56-6-16$ & 0.49 & n.d. & $\mathrm{S}$ & None & B. fragariae & Unknown & Flower & Calvert, MD \\
\hline $21-8-16$ & 0.88 & $>30$ & LR & None & B. fragariae & Unknown & Flower & Charleston, SC \\
\hline $77-6-16$ & 1.31 & $>100$ & MR & None & B. fragariae & Unknown & Flower & Harford, MD \\
\hline $27-2-16$ & 1.90 & $>100$ & MR & None & B. fragariae & Unknown & Flower & Lancaster, SC \\
\hline $7-3-15$ & 2.38 & $>100$ & MR & n.d. & B. fragariae & Unknown & Flower & Desha, AR \\
\hline $27-9-16$ & 3.04 & $>100$ & MR & None & B. fragariae & Unknown & Flower & Lancaster, SC \\
\hline $52-7-16$ & 3.11 & $>100$ & MR & None & B. fragariae & Unknown & Flower & Virginia Beach, VA \\
\hline $31-10-16$ & 3.37 & $>100$ & MR & None & B. fragariae & Unknown & Flower & Virginia Beach, VA \\
\hline $79-5-16$ & 3.48 & $>100$ & MR & None & B. fragariae & Unknown & Flower & Hanover, VA \\
\hline
\end{tabular}

x Abbreviation n.d. = not determined.

y Abbreviations S, LR, and MR stand for sensitive, low resistance, and medium resistance, respectively.

$\mathrm{z}$ Isolate was collected in strawberry field in Germany. 
sequence, description, and reference, is shown in Table 3. PCRs were performed in a volume of $25 \mu \mathrm{l}$ containing $10 \mathrm{ng}$ of DNA template, $0.4 \mu \mathrm{M}$ each primer, $200 \mu \mathrm{M}$ dNTP, $1 \times$ PCR buffer $(N e w$ England Biolabs), and $1 \mathrm{U}$ of Taq DNA polymerase (New England Biolabs). A PCR program of $94^{\circ} \mathrm{C}$ for $3 \mathrm{~min}$; followed by 34 cycles of $94^{\circ} \mathrm{C}$ for $40 \mathrm{~s}, 55^{\circ} \mathrm{C}$ for $40 \mathrm{~s}$, and extension at $72^{\circ} \mathrm{C}$ for $1 \mathrm{~min}$ and $30 \mathrm{~s}$; and a final step of $72^{\circ} \mathrm{C}$ for $10 \mathrm{~min}$ was used for the amplification of both $m r r l$ and $o s 1$. PCR products were verified by electrophoresis as described above and sent to the DNA laboratory at Arizona State University in Tempe, AZ. The mrrl sequences of B. cinerea isolate N11_K_W08b (GenBank accession number JX266761), Botrytis group S isolate D10_B_F1I06 (JX266766), and B. fragariae isolate D11-H-R4 (KX429733) and os 1 sequences of B. cinerea (AF435964) and B. fragariae isolate D13_D_F_Ju21 (KX429732) were used as reference sequences for identifying potential nucleotide mutations.
Osmotic stress assays and detection of 3-bp insertion in os 1 of B. fragariae. To determine the sensitivity of Botrytis spp. isolates to osmotic stress, a mycelial plug ( $5 \mathrm{~mm}$ in diameter) taken from a 4-day old culture grown on PDA was placed on minimal media [MM; (Hu et al. 2011)] and PDA media amended with $4 \%$ $\mathrm{NaCl}$. Petri dishes were incubated for 5 days at $22^{\circ} \mathrm{C}$ in darkness before taking measurements of the colony diameter. The susceptibility to osmotic stress was evaluated by calculating the mycelial growth inhibition compared with the control. Each isolate had three replicates and the experiment was conducted once.

To investigate the association between the 3-bp insertions in os 1 and reduced sensitivity to osmotic stress in the US $B$. fragariae isolates, primer pair os1 3bp-R and BF1_56_opt (Table 3) was used to detect the 3-bp insertion. The PCR amplification program was identical with that for $m r r l$ and osl amplification, except the extension duration was $30 \mathrm{~s}$ instead of $1 \mathrm{~min}$.

TABLE 2. Lesion diameter and infection frequency of fludioxonil-treated strawberry fruit inoculated with different phenotypes of Botrytis cinerea, Botrytis group $\mathrm{S}$, and Botrytis fragariae from two experiments

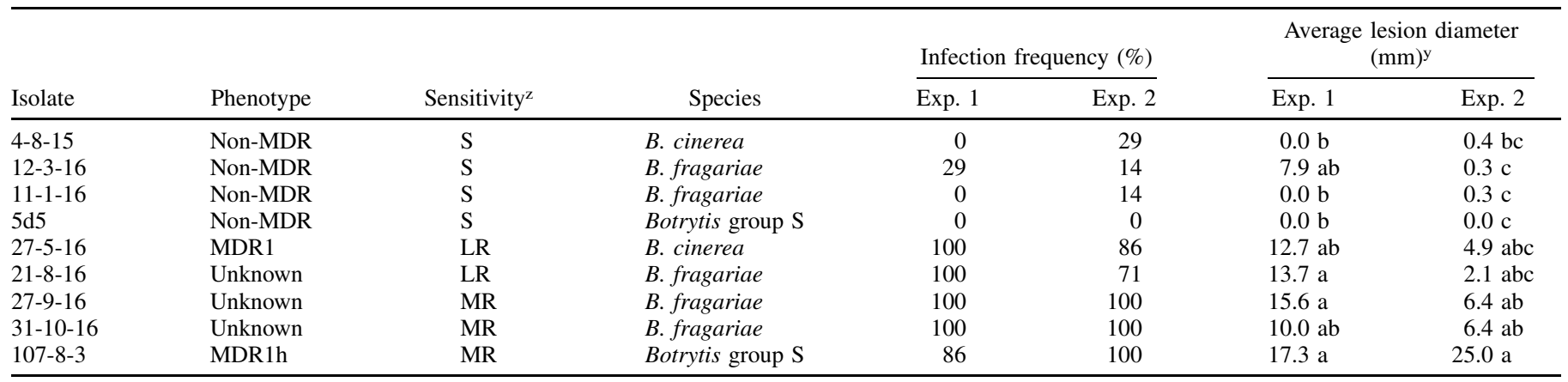

y Lesion diameters with the same letters are not significantly different $(P<0.05)$ according to a Dunn's multiple comparisons test.

z Abbreviations S, LR, and MR stand for sensitive, low resistance, and medium resistance, respectively, based on half-maximal effective concentration and 90\% mycelial growth inhibition values.

TABLE 3. Primers used in the study

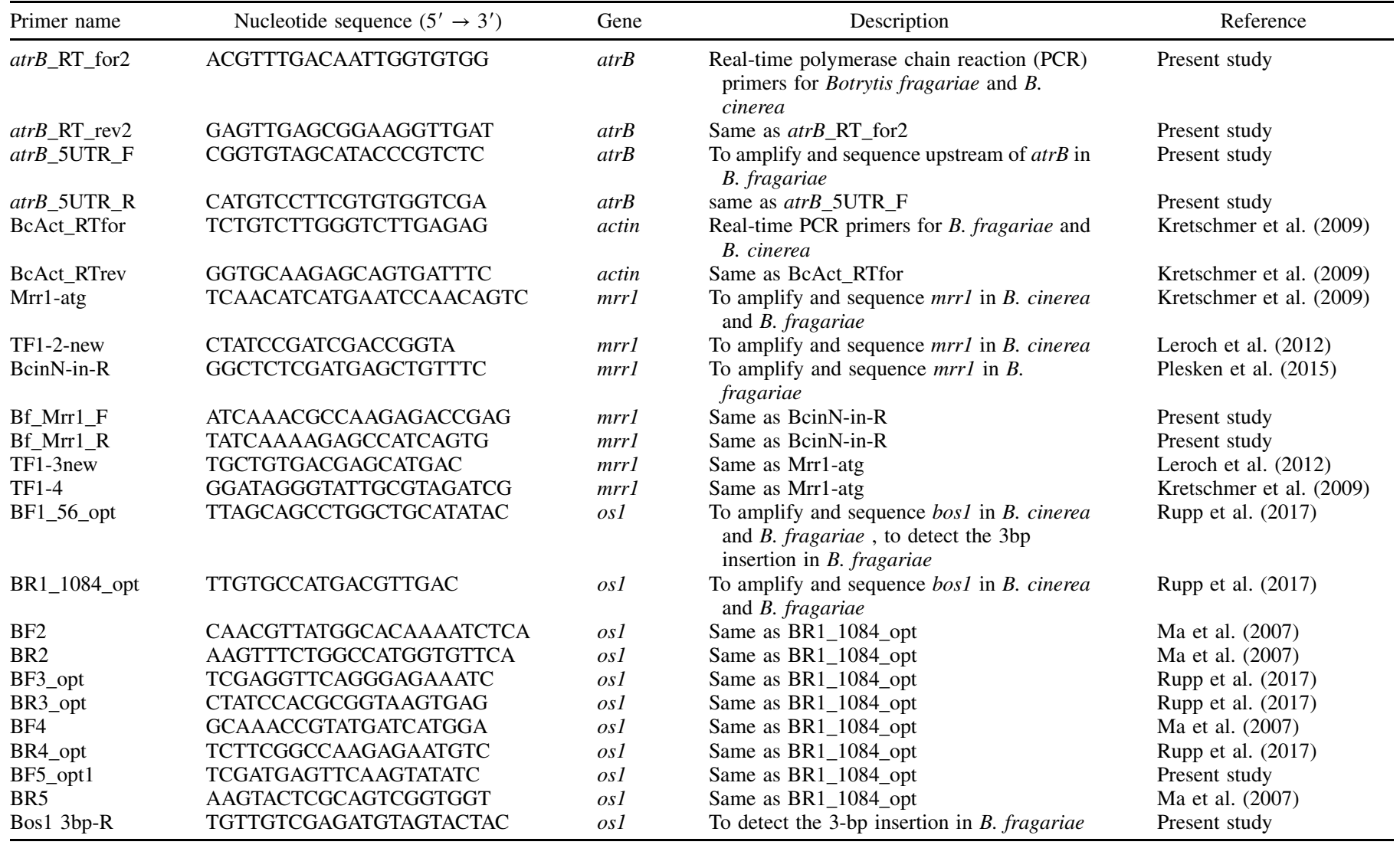


Relative expression analysis of $\operatorname{atr} \boldsymbol{B}$. The relative expression of $a t r B$ was determined in $B$. fragariae isolates with and without resistance to fludioxonil as well as MDR1h isolates of Botrytis group S. Single mycelial plugs were taken from a 4-day-old culture grown on PDA and transferred to flasks containing $50 \mathrm{ml}$ of MEB. Flasks were then placed in a shaker at $120 \mathrm{rpm}$ at room temperature for 4 days. Trizol reagent (Invitrogen, Carlsbad, CA, U.S.A.) was used to extract total RNA from mycelia following the manufacturer's protocol. Firststrand cDNA was then synthesized from the resulting RNA using a Bio-Rad iScript cDNA kit (Bio-Rad, Hercules, CA, U.S.A.).

For quantitative PCR analysis, primer pairs atrB_RT_for2/ atrB_RT_rev2 and BcAct_RTfor/BcAct_RTrev (Table 3) were designed to amplify the target gene $a t r B$ and reference gene actin, respectively. The PCR was conducted using iQ SYBR Green Supermix (Bio-Rad) according to the manufacturer's instructions. The amplification programs consisted of an initial denaturation at $95^{\circ} \mathrm{C}$ for $2 \mathrm{~min}$, followed by 45 cycles at $95^{\circ} \mathrm{C}$ for $15 \mathrm{~s}, 57^{\circ} \mathrm{C}$ for $15 \mathrm{~s}$, and $72^{\circ} \mathrm{C}$ for $15 \mathrm{~s}$. A melting curve analysis was also performed to verify the specificity of amplified products. Three replicates were used for each sample. Two experiments with new biological replicates were conducted independently. Analysis of significant difference procedures was conducted using JMP Pro 13.1.0 software at $P=0.05$ (SAS Institute Inc., Cary, NC, U.S.A.).

Investigations of upstream sequences and copy number of $\operatorname{atr} B$. Based on the $5^{\prime}$ flanking sequences of $\operatorname{atr} B$ obtained from the genome-sequenced $B$. cinerea isolate B05.10, primers $a t r B$ 5UTR_F and atrB_5UTR_R (Table 3) were designed to amplify and sequence upstream sequences of atr $B$ from $B$. fragariae. PCR amplification protocol was identical with that for $m r r l$ and os 1 amplification, except for a 2-min extension at $72^{\circ} \mathrm{C}$. PCR products were verified by electrophoresis as described above and sent to the DNA laboratory at Arizona State University in Tempe, AZ. Benchling (https://benchling.com/) was used for DNA sequence analysis. Promoter predictor software NNPP (http://www. fruitfly.org/seq_tools/promoter.html) was used to analyze promoter sequences.

To investigate the copy number of atrB in Botrytis spp. isolates with and without resistance to fludioxonil, the same primers used for relative expression analysis of $\operatorname{atr} B$ were used to amplify the $a t r B$ and actin genes from genomic DNA (Table 3). The PCR was conducted using iQ SYBR Green Supermix (Bio-Rad) according to the manufacturer's instructions. The amplification programs were identical with those of quantitative PCR analysis described above.

\section{RESULTS}

Identification of Botrytis spp. isolates from strawberry fields selected for the study. Of the 16 Botrytis isolates in this study, excluding those characterized previously (106-6-14, 107-814, and D11-H-R4), 5 were identified to be $B$. cinerea and 11 were $B$. fragariae (Table 1). Both species were collected primarily from blossoms but also from some fruit. B. fragariae isolates were found in South Carolina, Georgia, Maryland, Virginia, and Arkansas (Table 1).

Determination of sensitivity to fludioxonil of $B$. cinerea, Botrytis group $\mathrm{S}$, and $\boldsymbol{B}$. fragariae isolates. A spore-based microtiter assay determined fludioxonil sensitivity in all isolates. Overall, the $\mathrm{EC}_{50}$ values ranged from 0.04 to $3.48 \mu \mathrm{g} / \mathrm{ml}$ (Table 1). Based on the $\mathrm{EC}_{50}$ values and resistance categories described previously (Fernández-Ortuño et al. 2015), B. cinerea and Botrytis group $\mathrm{S}$ isolates with $\mathrm{EC}_{50}$ values ranging from 0.01 to $0.1,0.1$ to 0.5 , and 0.5 to $3 \mu \mathrm{g} / \mathrm{ml}$ were considered as sensitive (S), low resistant (LR), and moderately resistant (MR), respectively. Rupp et al. (2017) found that $\mathrm{EC}_{50}$ values of three fludioxonil-sensitive $B$. fragariae isolates ranged from 0.18 to $0.24 \mu \mathrm{g} / \mathrm{ml}$, which were higher than those of fludioxonil-sensitive $B$. cinerea isolates. Thus, B. fragariae isolates with $\mathrm{EC}_{50}$ values of 0.1 to $0.5,0.5$ to 1.0 , and 1.0 to $5.0 \mu \mathrm{g} / \mathrm{ml}$ were considered as $\mathrm{S}, \mathrm{LR}$, and $\mathrm{MR}$, respectively (Table 1 ). $\mathrm{EC}_{90}$ values are shown as $<3,>30$ but $>100$, and $>100 \mu \mathrm{g} / \mathrm{ml}$. The $\mathrm{EC}_{90}$ values of the majority of $\mathrm{S}$ and LR isolates were $<3 \mu \mathrm{g} / \mathrm{ml}$. All MR isolates, except 18-3-16, had $\mathrm{EC}_{90}$ values $>100 \mu \mathrm{g} / \mathrm{ml}$.

Detached-strawberry-fruit assays. The detached-fruit assay revealed that Botrytis isolates considered LR and MR tended to cause gray mold in higher frequencies, ranging from 71 to 100 and 0 to $29 \%$ for resistant (R, including $\mathrm{LR}$ and $\mathrm{MR}$ ) and $\mathrm{S}$ isolates respectively (Table 2). No lesions formed on the noninoculated control fruit. Experiments 1 and 2 yielded similar results, and a significant effect of inoculum on the lesion diameter was detected in both the first $(\mathrm{H}=39.420, P<0.001)$ and second $(\mathrm{H}=50.626, P<0.0001)$

\section{B. fragariae (Germany)}

$\mathbf{5}^{\prime}$
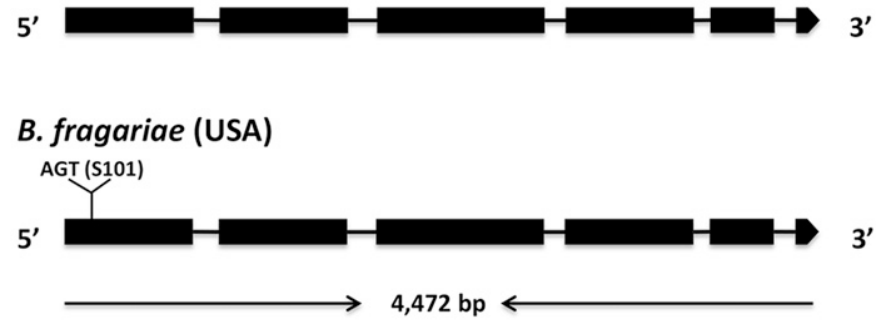

Fig. 1. Schematic of os 1 gene exon and intron organizations in Botrytis fragariae from Germany and the United States. Exons and introns are represented by dark rectangles and solid lines, respectively. The "Y" symbol indicates a position where an insertion event occurred.

TABLE 4. Sensitivity to cyprodinil, tolnaftate, and iprodione, and osl mutations in Botrytis spp. isolates with different phenotypes

\begin{tabular}{|c|c|c|c|c|c|c|}
\hline \multirow[b]{2}{*}{ Isolate } & \multicolumn{3}{|c|}{ Sensitivity $\left(\mathrm{EC}_{50}\right)^{\mathrm{y}}$} & \multirow[b]{2}{*}{ AA alteration in $o s 1$} & \multirow[b]{2}{*}{ Species } & \multirow[b]{2}{*}{ Phenotype } \\
\hline & Cyprodinil & Tolnaftate & Iprodione & & & \\
\hline $4-8-15$ & 0.099 & 1.13 & 0.49 & None & Botrytis cinerea & Non-MDR \\
\hline $27-5-16$ & 0.404 & $>10$ & $>100$ & I365S/D757 N/A1259T & B. cinerea & MDR1 \\
\hline $5 \mathrm{~d} 5$ & 2.47 & 1.62 & 4.66 & $\mathrm{~F} 127 \mathrm{~S} / \mathrm{I} 365 \mathrm{~N}$ & Botrytis group $\mathrm{S}$ & Non-MDR \\
\hline $6-3-15$ & 0.267 & $>10$ & $>11.22$ & n.d. & Botrytis group $\mathrm{S}$ & MDR1 \\
\hline $18-3-16$ & 0.102 & 4.31 & $>100$ & $\mathrm{~F} 127 \mathrm{~S} / \mathrm{I} 365 \mathrm{~N}$ & Botrytis group $\mathrm{S}$ & MDR1h \\
\hline $106-6-14$ & $>10$ & $>10$ & $>100$ & $\mathrm{I} 365 \mathrm{~N}$ & Botrytis group $\mathrm{S}$ & MDR1h \\
\hline $107-8-14$ & 0.376 & n.d. & $>100$ & I365S/A871V/A1259T & Botrytis group $\mathrm{S}$ & MDR1h \\
\hline D11-H-R4 ${ }^{z}$ & $>10$ & $>10$ & $>100$ & G367A/V368F & B. fragariae & Non-MDR \\
\hline $11-1-16$ & n.d. & 0.13 & n.d. & Insertion S101 & B. fragariae & Non-MDR \\
\hline $12-3-16$ & n.d. & 0.21 & n.d. & Insertion S101 & B. fragariae & Non-MDR \\
\hline $21-8-16$ & 0.084 & $>10$ & 1.75 & Insertion S101 & B. fragariae & Unknown \\
\hline $77-6-16$ & 0.089 & $>10$ & 1.83 & Insertion S101 & B. fragariae & Unknown \\
\hline $7-3-15$ & 0.103 & $>10$ & 3.36 & Insertion S101 & B. fragariae & Unknown \\
\hline $31-10-16$ & 1.376 & n.d. & 8.34 & n.d. & B. fragariae & Unknown \\
\hline
\end{tabular}

${ }^{y} \mathrm{EC}_{50}=$ half-maximal effective concentration; n.d. $=$ not determined.

$\mathrm{z}$ Isolate was collected in Germany. 
assays. Isolates considered LR and MR tended to have greater lesion diameters compared with the $\mathrm{S}$ isolates in both assays, with no exceptions (Table 2). Significant differences in lesion diameters were detected between some $\mathrm{R}$ and $\mathrm{S}$ isolates. For example, the lesion diameter of $B$. fragariae MR isolate 27-9-16 was significantly larger than all of the $\mathrm{S}$ isolates in both assays (Table 2).

Sequencing analysis of $\mathbf{m r r l}$ in Botrytis spp. isolates. The entire $m r r l$ gene, approximately $2,450 \mathrm{bp}$, was successfully amplified from all $B$. cinerea and $B$. fragariae isolates with seven primers (Table 3 ). Based on the $m r r l$ sequences, five $B$. cinerea isolates were further identified as Botrytis group $\mathrm{S}$ (Table 1) according to Leroch et al. (2012). No nucleotide mutations were found in $m r r l$ from the $B$. cinerea sensitive isolate (4-8-15), while amino acid substitutions of serine $(\mathrm{S})$ for threonine $(\mathrm{T})$ and asparagine $(\mathrm{N})$ for glycine $(\mathrm{G})$ were found at positions 449 and 702 , respectively, in the other fludioxonil-sensitive isolate (group $\mathrm{S}$; 5d5). D354Y and G702 N were detected in one B. cinerea LR isolate (6-3-15), whereas the other LR isolate (27-5-16) had the R351C mutation. All B. cinerea MR isolates belonging to Botrytis group $\mathrm{S}$ possessed the $\mathrm{L} 497$ deletion in $m r r l$, indicating them to be MDR $1 \mathrm{~h}$ (Leroch et al. 2012). None of the $B$. fragariae isolates examined had mutations in the mrrl gene (Table 1). The mrrl sequences of B. fragariae isolate 79-5-16; Botrytis group $\mathrm{S}$ isolates $18-3-16,5 \mathrm{~d} 5$, and 6-3-15; and B. cinerea isolates 27-5-16 and 4-8-15 were deposited in GenBank under accession numbers MH721887, MH721889. MH721890, MH721891, MH721888, and MH721892, respectively.

Sensitivity to iprodione, cyprodinil, and tolnaftate and sequencing analysis of $\boldsymbol{o s} 1$. In order to investigate crossresistance patterns between PPs (e.g., fludioxonil) and DCs (e.g., iprodione), and between PPs and anilinopyrimidines (e.g., cyprodinil), the sensitivity to iprodione and cyprodinil was determined using microtiter assays. Tolnaftate was also included in the sensitivity assays because resistance to this product indicates increased drug efflux pump activity in MDR phenotypes (Kretschmer et al. 2009). No cross-resistance was observed between fludioxonil and cyprodinil. For example, $B$. cinerea isolates 6-3-15 and 18-3-16 resistant to fludioxonil were both sensitive to cyprodinil (Table 4). $\mathrm{EC}_{50}$ values of all MDR isolates, including MDR1 and MDR1h, ranged from 4.31 to $>10 \mu \mathrm{g} / \mathrm{ml}$ for tolnaftate, whereas $\mathrm{EC}_{50}$ values of non-MDR isolates ranged from 0.13 to $1.62 \mu \mathrm{g} / \mathrm{ml}$ (Table 4). For iprodione, $\mathrm{EC}_{50}$ of $B$. cinerea isolates (including group $\mathrm{S}$ ) and $B$. fragariae isolates ranged from 0.49 to $>100 \mu \mathrm{g} / \mathrm{ml}$ and 1.75 to $>100 \mu \mathrm{g} / \mathrm{ml}$, respectively.

The entire os 1 gene sequence was successfully cloned from $B$. cinerea and $B$. fragariae isolates. The gene was approximately 4,472 bp in length for both species and consisted of 5 introns and 6 exons (Fig. 1). The analysis of os 1 sequences revealed that iprodione resistance was linked to a variety of mutations. For example, I365S, D757 N, and A1259T were found in B. cinerea isolate 27-5-16, whereas F127S and I365 $\mathrm{N}$ were found in the Botrytis group S isolate $5 \mathrm{~d} 5$. All of the isolates resistant to iprodione, except 106-6, contained two or more mutations in os 1 (Table 4). A 3-bp insertion was found at position 101 of os 1 , leading to a serine insertion in some fludioxonil-sensitive and -resistant isolates of $B$. fragariae (Fig. 1; Table 4). The os 1 sequence of B. fragariae isolate 27-9-16 was deposited in GenBank under accession number MH721893.

Sensitivity of Botrytis spp. isolates to $\mathrm{NaCl}$ and investigation of the 3-bp insertion in os 1 . Except for the German isolate (D11-H-R4), mycelial growth of $B$. fragariae isolates was inhibited more by $\mathrm{NaCl}$-amended media compared with $B$. cinerea isolates (Fig. 2). On MM, the inhibition rate of the U.S. B. fragariae isolates ranged from 62.5 to $67.6 \%$, whereas those of $B$. cinerea isolates ranged from 20.0 to $48.8 \%$. Similarly, the inhibition rate of the U.S. B. fragariae and $B$. cinerea isolates (including Botrytis group S) ranged from 61.3 to 71.8 and 16.8 to $41.1 \%$, respectively, on PDA (Fig. 2). PCR primer pair os $13 \mathrm{bp}-\mathrm{R}$ and BF1_56_opt detected the 3-bp insertion in all U.S. B. fragariae isolates (Table 1) but not in the German isolate D11-H-R4 (Fig. 1). In addition, the 3-bp insertion was absent in all $B$. cinerea isolates tested in the study (Table 4).

Relative expression of atrB in Botrytis spp. isolates with and without resistance to fludioxonil. Quantitative real-time PCR was performed to investigate whether $a t r B$ was differentially

\section{B. fragariae}

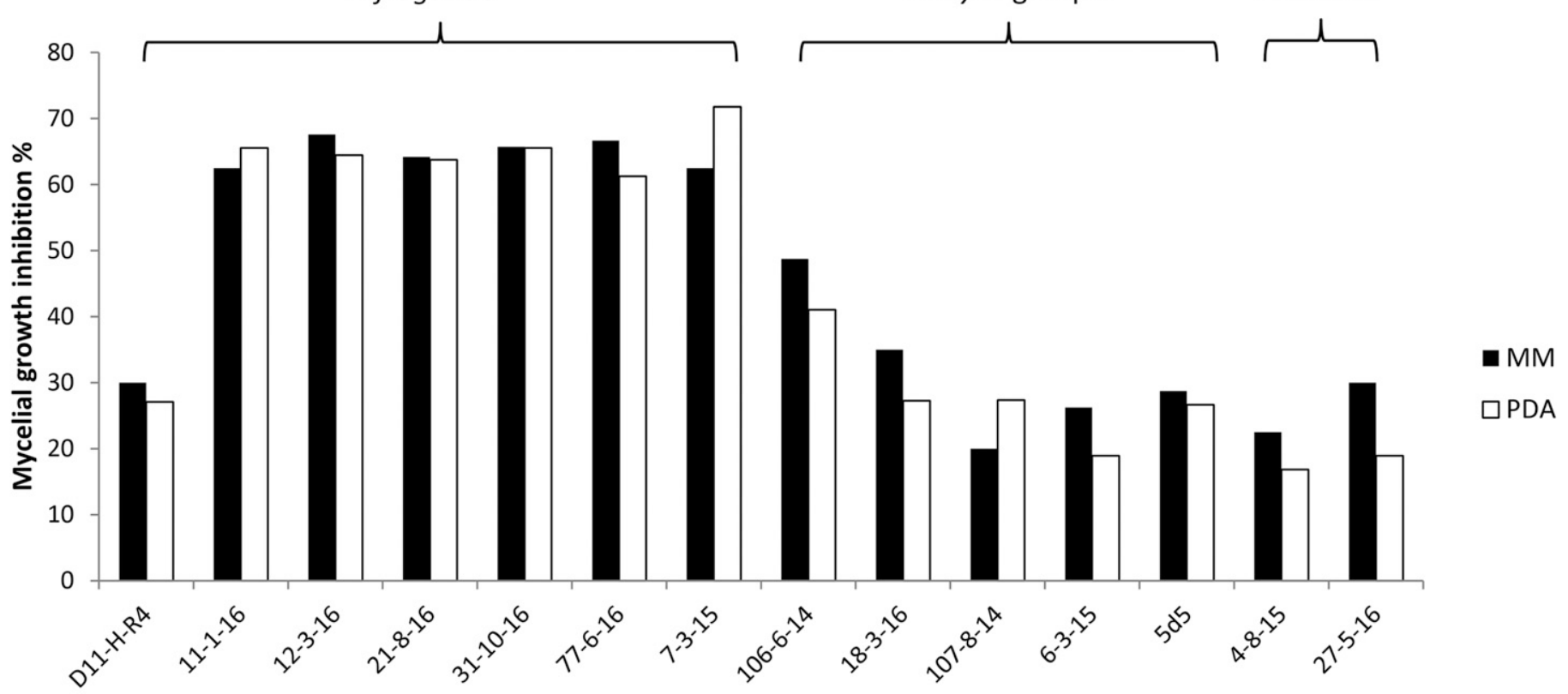

Botrytis spp. isolates

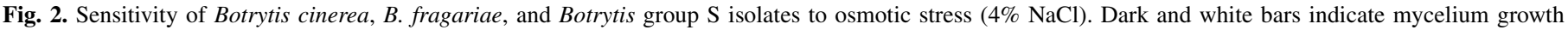
inhibition $(\%)$ of individual isolates grown on minimal medium (MM) and potato dextrose agar (PDA), respectively. 
expressed in B. fragariae isolates sensitive or resistant to fludioxonil. Botrytis group S MDR1h isolates 106-6-14 and 107-814 were included in the experiments to enable a direct comparison between two species. The mean values of relative expression ranged from 1.3 to $2.9,15.3$ to 21.3 , and 4.4 to 5.1 for $B$. fragariae sensitive isolates, B. fragariae resistant isolates, and B. cinerea MDR1h isolates, respectively (Fig. 3). The highest expression level of atrB was found in $B$. fragariae resistant isolates compared with B. fragariae sensitive isolates and MDR1h isolates. B. fragariae sensitive isolate D11-H-R4 had the lowest relative expression of $\operatorname{atr} B$, while the highest expression was detected in the resistant isolate 7-3-15. A significantly higher $(P<0.05)$ expression level of atrB was found in MDR1h isolates 106-6-14 and 107-8-14 than in B. fragariae sensitive isolates (D11-H-R4, 11-1-16, and 12-3-16).

Analyses of upstream sequences and copy number of atrB. In an attempt to explain the molecular basis of the $\operatorname{atr} B$ overexpression in $B$. fragariae isolates resistant to fludioxonil, the upstream sequence was searched for variations and the copy number of the $\operatorname{atr} B$ gene was investigated. The 1,370-bp upstream sequences were identical between four resistant and four sensitive B. fragariae isolates, except for a 41-bp insertion (5'CGGAGA TAGGTGAATTCGAACACATTAGATCACTCACGGCG3') in one resistant isolate (77-6-16). The insertion was located 1,050 bases upstream of the start codon of $\operatorname{atr} B$. The insertion did not contain predicted promoter sequences. The results of quantitative PCR showed less than twofold difference in mean value of relative copy number among five isolates tested, ranging from 1.2 to 1.9 (Fig. 4). The atrB upstream sequences of $B$. fragariae isolates 3110-16, 27-2-16, 12-3-16, 11-1-16, and 77-6-16 were deposited in GenBank under accession numbers MH721882, MH721883, MH721884, MH721885, and MH721886, respectively.

\section{DISCUSSION}

Two mechanisms conferring resistance to fludioxonil in $B$. cinerea have been reported. The first and most common is the overexpression of $\operatorname{atr} B$, leading to active removal of the fungicide from of the cell with this membrane-bound $\mathrm{ABC}$ transporter. The overexpression has always been linked to $\mathrm{mrrl}$ mutations in both B. cinerea and B. fragariae from Europe and the United States (Fernández-Ortuño et al. 2015; Kretschmer et al. 2009; Li et al. 2014; Rupp et al. 2017). This mechanism of resistance is associated with $\mathrm{EC}_{50}$ levels ranging from 0.16 to $0.4 \mu \mathrm{g} / \mathrm{ml}$ for MDR1 isolates and 0.75 to $3.1 \mu \mathrm{g} / \mathrm{ml}$ for MDR $1 \mathrm{~h}$ isolates of $B$. cinerea and Botrytis group S (Fernández-Ortuño et al. 2015; Rupp et al. 2017), and from

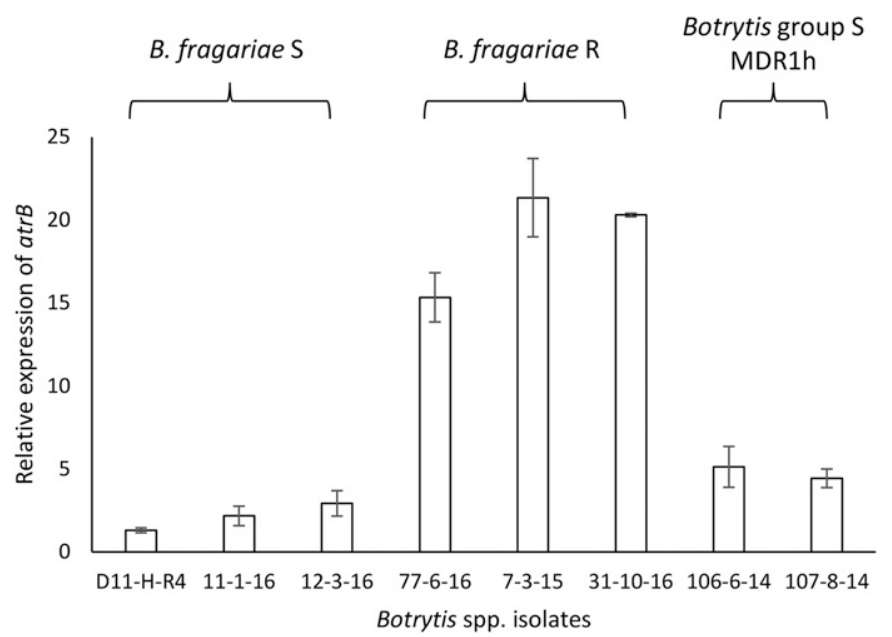

Fig. 3. Relative expression of the atrB gene in Botrytis spp. isolates with differential sensitivity to fludioxonil. The $a t r B$ expression was normalized with the actin gene expression and then calibrated to the values of mRNA amount based on the isolate with the lowest amount of atrB mRNA.
0.86 to $1.0 \mu \mathrm{g} / \mathrm{ml}$ for MDR1 isolates of $B$. fragariae (Rupp et al. 2017). The other mechanism is based on mutations in os 1 leading to high levels of resistance to fludioxonil $\left(\mathrm{EC}_{50}\right.$ values $\left.>100 \mu \mathrm{g} / \mathrm{ml}\right)$ in $B$. cinerea field isolates from China, and the mutations were located in the HAMP domains of the N-terminal region (Ren et al. 2016). In agreement with the previous studies, the $\mathrm{EC}_{50}$ values of MDR1 or MDR1h isolates fell into the same range of each phenotype (Table 1), allowing for a valid comparison of $\mathrm{EC}_{50}$ values of U.S. $B$. fragariae isolates with other resistant phenotypes in this study.

Overexpression of target genes or ABC transporters has been found to confer fungicide resistance in many fungal pathogens. In most cases, the overexpression was caused by rearrangement of upstream promoters or mutations in transcription factors, which constitutively regulate gene expression (Kretschmer et al. 2009; Luo and Schnabel 2008; Schnabel and Jones 2001). In this study, the atr $B$ gene was constitutively expressed in all untreated $B$. fragariae isolates with resistance to fludioxonil. Only minor differences were found between fludioxonil-treated and -untreated $B$. fragariae resistant isolates in $a t r B$ expression (data not shown). Although a 41-bp insertion was present at position $1,050 \mathrm{bp}$ of the $\operatorname{atr} B$ upstream region in the resistant isolate 77-6-16, it was absent in other resistant isolates in which atrB was consistently highly expressed. The presence of the insertion did not alter upstream promoter sequences of $a t r B$ according to NNPP predication, nor did the insertion contain a promoter sequence (data not shown). Final proof of involvement for fludioxonil resistance was that the same 41-bp insertion was found in a $B$. fragariae sensitive isolate (data not shown), which further confirmed the disassociation with the $a t r B$ overexpression.

Gene duplication and amplification is considered an important adaptive mechanism in bacteria in response to the presence of antibiotics (Sandegren and Andersson 2009). An increase in gene copy number can be responsible for rapid evolution of resistance of plants to herbicides (Koo et al. 2018). However, this mechanism has not been correlated with fungicide resistance in plant pathogens and our results also did not support gene duplication as a viable mechanism for resistance to fludioxonil. Therefore, the molecular basis for the high level of atrB expression in our resistant B. fragariae isolates remains elusive but could be linked to a cryptic transcription factor different from $\mathrm{mrrl}$. A previous study has shown that R632I mutation in $m r r l$ was not detected in lab mutants of $B$. cinerea with $\mathrm{EC}_{50}$ values $>50 \mu \mathrm{g} / \mathrm{ml}$ for fludioxonil, indicating that the fungus may be using additional mechanisms to mediate resistance (Jurick et al. 2017). However, other possible MDR1-related mutations or MDR1h's deletion in $\mathrm{mrrl}$ were not

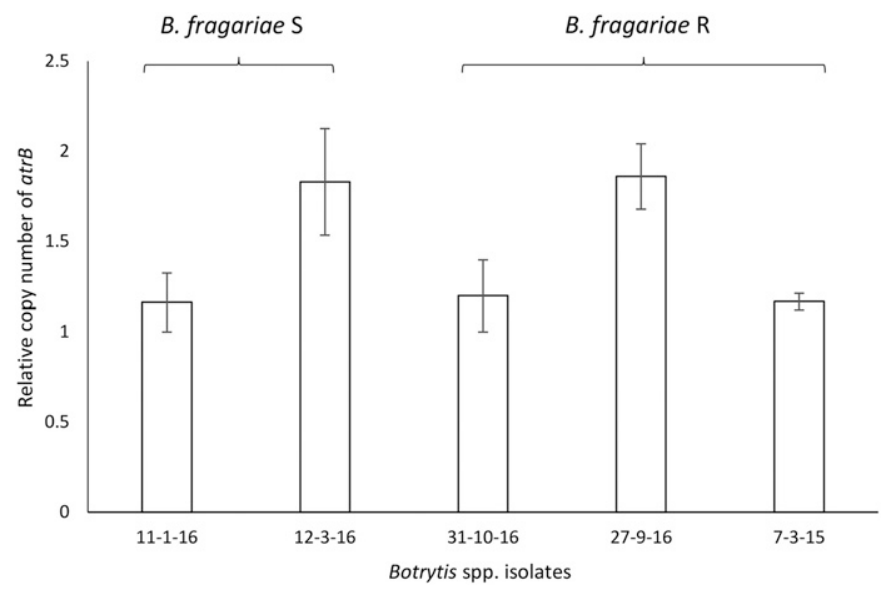

Fig. 4. Relative copy number of the $\operatorname{atr} B$ gene in Botrytis spp. isolates with differential sensitivity to fludioxonil. The $a t r B$ copy number was normalized with the actin gene copy number and then calibrated to the values of genomic DNA (gDNA) amount based on the isolate with the lowest amount of atrB gDNA. 
investigated in the same study. In fact, a high level of resistance to fludioxonil in $B$. cinerea is usually correlated with os 1 mutations and none of the mutations in $\mathrm{mrrl}$ revealed thus far can lead to $\mathrm{EC}_{50}$ values $>50 \mu \mathrm{g} / \mathrm{ml}$ (see above for details).

Positive correlations have been observed between the level of fludioxonil resistance and $\operatorname{atr} B$ expression. $\operatorname{atr} B$ is up to 3 -fold more expressed in MDR1h isolates compared with MDR1 isolates and $>100$-fold more expressed than in $B$. cinerea sensitive isolates (Fernández-Ortuño et al. 2015; Li et al. 2014). B. fragariae isolates tended to have higher levels of atrB expression, resulting in an intrinsically lower sensitivity to fludioxonil compared with B. cinerea and Botrytis group S (Rupp et al. 2017). For example, similar levels of atrB expression were found in $B$. fragariae MDR1 isolates and Botrytis group S MDR1h isolates. In our study, atrB expression of fludioxonil-sensitive $B$. fragariae isolates was only slightly lower than in Botrytis group S MDR1h isolates, which is consistent with the previous study (Rupp et al. 2017). Interestingly, the atrB expression of our fludioxonil MR B. fragariae isolates was approximately fourfold higher, on average, than Botrytis group $\mathrm{S}$ MDR1h isolates, and revealed the highest resistance levels $\left(\mathrm{EC}_{50}\right.$ range from 0.88 to $3.48 \mu \mathrm{g} / \mathrm{ml}$ ) of all resistant phenotypes identified in Europe or the United States thus far.

Partial resistance to cyprodinil has been associated with fludioxonil resistance in Botrytis MDR1 and MDR1h isolates (Kretschmer et al. 2009; Leroch et al. 2012). However, in our study, $B$. fragariae isolates with resistance to fludioxonil were sensitive to cyprodinil. Thus, at least in our isolates, $\operatorname{atr} B$ was not a genetic determinant of partial resistance to cyprodinil. On the other hand, resistance to tolnaftate was present in the fludioxonil-resistant $B$. fragariae isolates, confirming that atr $B$ overexpression confers resistance to tolnaftate in both $B$. cinerea and $B$. fragariae. Although slightly lower sensitivity to iprodione was observed in those $B$. fragariae isolates compared with $B$. cinerea isolate 4-8-1, no clear evidence was found to support cross-resistance between iprodione and fludioxonil. Rupp et al. (2017) showed that the $\mathrm{EC}_{50}$ values of four European B. fragariae sensitive isolates ranged from 0.79 to $1.95 \mu \mathrm{g} / \mathrm{ml}$ for iprodione, which were lower than but comparable with those of our $B$. fragariae isolates. The slightly higher tolerance to iprodione in the U.S. B. fragariae could be due to the 3-bp insertion in os 1 . Iprodione resistance found in all of the MDR1 and MDR1h isolates was correlated with mutations in os 1, indicating that $a t r B$ overexpression in Botrytis isolates may not confer resistance to DCs such as iprodione.

Increased sensitivity to osmotic stress has been found in Botrytis isolates with moderate resistance to fludioxonil but not in isolates with low resistance (Li et al. 2014). A similar pattern was found among B. cinerea and Botrytis group S isolates in our study. It is interesting that all B. fragariae isolates collected in the United States, including both fludioxonil-sensitive and -resistant isolates, were highly sensitive to $4 \% \mathrm{NaCl}$, indicating that osmotic sensitivity remained unaffected by the overexpression of atr $B$ in the resistant $B$. fragariae isolates. Increased sensitivity to osmotic stress has been linked to mutations in osmoregulation genes such as osl (Ren et al. 2016) and os 2 (Zhang et al. 2002). Whether the 3-bp insertion in the os 1 coding region found in all U.S. B. fragariae isolates was responsible for the increased osmotic sensitivity is unknown. Investigation of osmotic stress in more European B. fragariae isolates will further reveal the role of the 3-bp insertion. In addition, the 3-bp insertion may serve as a molecular marker for U.S. B. fragariae. A variety of factors, including mutation, gene migration, selection, population size, and mating system, can contribute to genetic change within a population (McDonald 1997). A genetic analysis of European and U.S. $B$. fragariae populations may further confirm their genetic differences and reveal genetic structure within and among populations.

A follow-up experiment was conducted to investigate potential synergistic interaction between $\mathrm{NaCl}$ and fludioxonil to hopefully take advantage of the increased osmotic sensitivity for practical applications. The isolates were grown on PDA amended with $\mathrm{NaCl}$ at $0.03,0.1,0.3$, or $1 \%$ plus fludioxonil at $0.05 \mu \mathrm{g} / \mathrm{ml}$, in comparison with fludioxonil at $0.05 \mu \mathrm{g} / \mathrm{ml}$ only. No synergy was observed (data not shown). Botrytis isolates in the eastern U.S. strawberry fields have developed resistance to a wide range of chemical classes of fungicides. Thus far, fludioxonil is one of the few single-site fungicides to which a majority of $B$. cinerea isolates remain sensitive (Hu et al. 2016). B. fragariae tended to have a higher level of tolerance to fludioxonil compared with $B$. cinerea (Rupp et al. 2017). Moreover, all of the resistant B. fragariae isolates found in this study were able to grow on PDA amended with fludioxonil at $100 \mu \mathrm{g} / \mathrm{ml}$, except for 21-8-16 (Table 1). Given that B. cinerea and $B$. fragariae exist in sympatry (Hu et al. 2018), B. fragariae isolates, particularly the resistant isolates, possess the selective advantage. Monitoring of the prevalence of Botrytis spp. at different berry growth stages may further understanding of the disease epidemiology.

In conclusion, overexpression of $a t r B$ was found to be the likely cause of fludioxonil resistance but, uncharacteristically, no variations in $m r r l$ were identified in U.S. B. fragariae isolates. This suggests that other mechanisms may be involved in regulation of atrB expression. A comparative genomic analysis on $B$. fragariae resistant and sensitive isolates may be necessary to uncover the driving forces of $a t r B$ overexpression in this Botrytis sp.

\section{ACKNOWLEDGMENTS}

Technical Contribution No. 6733 of the Clemson University Experiment Station.

\section{LITERATURE CITED}

Chen, S. N., Luo, C. X., Hu, M. J., and Schnabel, G. 2016. Fitness and competitive ability of Botrytis cinerea isolates with resistance to multiple chemical classes of fungicides. Phytopathology 106:997-1005.

Dowling, M. E., Hu, M.-J., and Schnabel, G. 2017. Identification and characterization of Botrytis fragariae isolates on strawberry in the United States. Plant Dis. 101:1769-1773.

Dowling, M. E., Hu, M.-J., and Schnabel, G. 2018. Fungicide resistance in Botrytis fragariae and species prevalence in the Mid-Atlantic United States. Plant Dis. 102:964-969.

Faretra, F., and Pollastro, S. 1993. Isolation, characterization and genetic analysis of laboratory mutants of Botryotinia fuckeliana resistant to the phenylpyrrole fungicide CGA 173506. Mycol. Res. 97:620-624.

Fernández-Ortuño, D., Grabke, A., Bryson, P. K., Amiri, A., Peres, N. A., and Schnabel, G. 2014. Fungicide resistance profiles in Botrytis cinerea from strawberry fields of seven Southern U.S. states. Plant Dis. 98:825-833.

Fernández-Ortuño, D., Grabke, A., Li, X., and Schnabel, G. 2015. Independent emergence of resistance to seven chemical classes of fungicides in Botrytis cinerea. Phytopathology 105:424-432.

Fillinger, S., Ajouz, S., Nicot, P. C., Leroux, P., and Bardin, M. 2012. Functional and structural comparison of pyrrolnitrin- and iprodione-induced modifications in the class III histidine-kinase bos 1 of Botrytis cinerea. PLoS One 7:e42520.

Hu, M.-J., Cox, K. D., and Schnabel, G. 2016. Resistance to increasing chemical classes of fungicides by virtue of "selection by association" in Botrytis cinerea. Phytopathology 106:1513-1520.

Hu, M.-J., Dowling, M. E., and Schnabel, G. 2018. Genotypic and phenotypic variations in Botrytis spp. isolates from single strawberry flowers. Plant Dis. 102:179-184.

Hu, M.-J., Grabke, A., Dowling, M. E., Holstein, H. J., and Schnabel, G. 2015. Resistance in Colletotrichum siamense from peach and blueberry to thiophanate-methyl and azoxystrobin. Plant Dis. 99:806-814.

Hu, M.-J., Luo, C.-X., Grabke, A., and Schanbel, G. 2011. Selection of suitable medium to determine sensitivity of Monilinia fructicola mycelium to SDHI fungicides. J. Phytopathol. 159:616-620.

Jurick, W. M., II, Macarisin, O., Gaskins, V. L., Park, E., Yu, J., Janisiewicz, W., and Peter, K. A. 2017. Characterization of postharvest fungicideresistant Botrytis cinerea isolates from commercially stored apple fruit. Phytopathology 107:362-368.

Koo, D.-H., Jugulam, M., Putta, K., Cuvaca, I. B., Peterson, D., Currie, R. S., Friebe, B., and Gill, B. S. 2018. Gene duplication and aneuploidy trigger rapid evolution of herbicide resistance in common waterhemp. Plant Physiol. 176:1932-1938. 
Kretschmer, M., Leroch, M., Mosbach, A., Walker, A. S., Fillinger, S., Mernke, D., Schoonbeek, H. J., Pradier, J. M., Leroux, P., and De Waard, M. A. 2009. Fungicide-driven evolution and molecular basis of multidrug resistance in field populations of the grey mould fungus Botrytis cinerea. PLoS Pathog. 5:e1000696.

Leroch, M., Plesken, C., Weber, R. W. S., Kauff, F., Scalliet, G., and Hahn, M. 2012. Gray mold populations in German strawberry fields are resistant to multiple fungicides and dominated by a novel clade closely related to Botrytis cinerea. Appl. Environ. Microbiol. 79:159-167.

Leroux, P., Chapeland, F., Desbrosses, D., and Gredt, M. 1999. Patterns of cross-resistance to fungicides in Botryotinia fuckeliana (Botrytis cinerea) isolates from French vineyards. Crop Prot. 18:687-697.

Li, X., Fernández-Ortuño, D., Grabke, A., and Schnabel, G. 2014. Resistance to fludioxonil in Botrytis cinerea isolates from blackberry and strawberry. Phytopathology 104:724-732.

Luo, C. X., and Schnabel, G. 2008. The cytochrome P450 lanosterol 14 $\alpha$ demethylase gene is a demethylation inhibitor fungicide resistance determinant in Monilinia fructicola field isolates from Georgia. Appl. Environ. Microbiol. 74:359-366.

Ma, Z., Yan, L., Luo, Y., and Michailides, T. J. 2007. Sequence variation in the two-component histidine kinase gene of Botrytis cinerea associated with resistance to dicarboximide fungicides. Pestic. Biochem. Physiol. 88:300-306.

McDonald, B. A. 1997. The population of genetics of fungi: Tools and techniques. Phytopathology 87:448-453.

Plesken, C., Weber, R. W. S., Rupp, S., Leroch, M., and Hahn, M. 2015. Botrytis pseudocinerea is a significant pathogen of several crop plants but susceptible to displacement by fungicide-resistant B. cinerea strains. Appl. Environ. Microbiol. 81:7048-7056.

Ren, W., Shao, W., Han, X., Zhou, M., and Chen, C. 2016. Molecular and biochemical characterization of laboratory and field mutants of Botrytis cinerea resistant to fludioxonil. Plant Dis. 100:1414-1423.

Rupp, S., Plesken, C., Rumsey, S., Dowling, M., Schnabel, G., Weber, R. W. S., and Hahn, M. 2017. Botrytis fragariae, a new species causing gray mold on strawberries, shows high frequencies of specific and efflux-based fungicide resistance. Appl. Environ. Microbiol. 83:e00269-17.

Sandegren, L., and Andersson, D. I. 2009. Bacterial gene amplification: Implications for the evolution of antibiotic resistance. Nat. Rev. Microbiol. 7: 578-588.

Schnabel, G., Hu, M., and Fernández-Ortuño, D. 2015. Monitoring resistance by bioassay: Relating results to field use using culturing methods. Pages 281-293 in: Fungicide Resistance in Plant Pathogens: Principles and a Guide to Practical Management. H. Ishii and D. Hollomon, eds. Springer, Japan KK, Tokyo, Japan.

Schnabel, G., and Jones, A. L. 2001. The $14 \alpha$-demethylasse (CYP51A1) gene is overexpressed in Venturia inaequalis strains resistant to myclobutanil. Phytopathology 91:102-110.

Stammler, G., and Speakman, J. 2006. Microtiter method to test the sensitivity of Botrytis cinerea to boscalid. J. Phytopathol. 154:508-510.

Zhang, Y., Lamm, R., Pillonel, C., and Xu, J. R. 2002. Osmoregulation and fungicide resistance: The Neurospora crassa os-2 gene encodes a HOG1 mitogen-activated protein kinase homologue. Appl. Environ. Microbiol. 68: $532-538$ 